\title{
Low-carbon Asia: technical contributions to an ambitious goal for sustainability
}

\author{
Chew Tin Lee ${ }^{1,3} \cdot$ Haslenda Hashim ${ }^{1,3} \cdot$ Chin Siong $\mathrm{Ho}^{2,3} \cdot$ Jiří Jaromír Klemeš $^{4}$
}

Published online: 6 October 2016

(c) Springer-Verlag Berlin Heidelberg 2016

Despite a substantial effort orchestrated to accelerate green development worldwide, many challenges remain, notably in Asia where the economic growth has been accelerating. Decoupling high greenhouse gases emission without compromising the economic growth is a great challenge. The coordinated efforts at different levels covering from top-down and bottom-up measures are essential to implement the low-carbon emissions scenarios with reduced carbon footprints. Efforts such as through governmental policy and incentives, investment in green technology and promotional activities by NGOs to promote green transformation towards low-carbon emissions development are ongoing. The progress has not been always fast enough due to the gaps among the key stakeholders including the central and local governments, experts and business entities and the community at large. Organisation of the international conference to promote environmentally friendly and sustainable transformation is important to bridge these gaps. The conference series of International Conference of Low Carbon Asia 2015 (ICLCA'15) aims to accelerate the green development in Asia. The 1st ICLCA'15 conference

Chew Tin Lee

ctlee@utm.my

1 Faculty of Chemical and Energy Engineering, Universiti Teknologi Malaysia (UTM), 81310 Johor Bahru, Johor, Malaysia

2 Faculty of Built Environment, Universiti Teknologi Malaysia (UTM), 81310 Johor Bahru, Johor, Malaysia

3 Low Carbon Asia Research Centre, Universiti Teknologi Malaysia (UTM), 81310 Johor Bahru, Johor, Malaysia

4 Faculty of Information Technology and Bionics, Pázmány Péter Catholic University, Práter u. 50/a, Budapest 1083, Hungary
$<$ www.utm.my/iclca2015/> was held in Johor Bahru, Malaysia, from 11 to 13 October 2015, and it was held in conjunction with the 4th Annual Meeting of Low Carbon Asia Research Network (LoCARNet) in Malaysia with the theme "Positive Action from Asia-Towards COP21 and Beyond" <lcs-rnet.org/locarnet_meetings/2015/09/1371>. The LoCARNet is a network for multi-layered stakeholders to promote research cooperation related to low-carbon growth and policy making. The double event was attended by 200 international scientists and policy makers from research institutions, government agencies, municipalities, universities and NGOs including from Cambodia, China, Hungary, India, Indonesia, Japan, Laos, Malaysia, Philippines, Singapore, Thailand and Vietnam. The double event culminated in the launch of a regional Low-carbon Emission Declaration, the "LoCARNet Iskandar Malaysia Declaration" <lcs-rnet.org/locarnet_meetings/2015/10/ $1398>$ that was disseminated at the 21st yearly session of the Conference of the Parties (COP21), Paris, France $<$ www.cop21paris.org $>$.

A Scientific Committee consisting of 32 world leading personalities reviewed the 99 papers submitted for the oral and poster presentation. The authors hailed from 10 countries mainly from the East and Southeast Asia. Following the further selection procedures, 32 invitations have been sent to the ICLCA' 15 authors to prepare articles, out of which 15 have been finally accepted to this Special Issue of Clean Technologies and Environmental Policy entitled "Mobilising the Potential towards Low Carbon Society in Asia".

A total of eight major thematic topics has been announced for the conference, indicating its multidisciplinary and holistic approach towards finding solutions for a better future. Those topics include: 
1. Comprehensive and continual support package for the creation of scientific national and city-level climate policies in Asia.

2. Recent developments in green technologies in Asia.

3. Environmental impact.

4. Cleaner technologies for waste, water, energy, transportation, building.

5. Inventory tools in Asia (e.g. Life Cycle Assessment; GOSAT; Measuring, Reporting and Verification).

6. International and Asian reports, critics and best practice guidelines.

7. Partnership and linkages to enable low-carbon emission Asia.

8. Science to action and implementation of low-carbon emission technologies and policies.

The conference series are going to continue, and the 2nd ICLCA'16 will be held in Kuala Lumpur, Malaysia, from
23 to 25 November $2016<$ www.utm.my/iclca $>$. An early consensus has been reached, and the 3rd ICLCA'17 will be held in Bangkok to strengthen the regional collaboration for climate change.

This Special Issue of Clean Technologies and Environmental Policy has been published within a short period, which would not have been possible without the valuable help from about 63 reviewers who have selflessly spent a great deal of their efforts on adjusting the professional qualities of the submitted manuscripts to the high standards of the journal. The Guest Editors of this Special Issue would like to thank all of them and especially those engaged in multiple reviewing and also involved in the ICLCA'15 Scientific Committee.

The CTEP journal publisher-Springer Nature, the Editor in Chief with the Regional Editors deserve many thanks for their support and encouragement as well. 